\title{
THE GREEK BANDIT FOTIOS GIAGOULAS: AN INTRODUCTION TO HIS MUMMIFIED HEAD AND FUTURE CONSERVATION AIMS
}

\author{
Anastasia Karamanou ${ }^{1}$, Maria Stefanidou $^{2}$ \\ ${ }^{1}$ Department of Conservation of Archaeological Antiquities and Works of Art, \\ T.E.I. of Athens, Athens, Greece \\ ${ }^{2}$ Department of Forensic Medicine and Toxicology, School of Medicine, \\ University of Athens, Athens, Greece
}

\begin{abstract}
This investigation presents the level of preservation and examination plan for a mummified head from the early $20^{\text {th }}$ century. The head belongs to a legendary Greek bandit displayed at the Museum of Criminology, Athens. This investigation aimed to understand the mummification process employed, the conservation history of the head, record the current preservation status using photography, and to recognise evidence of biological deterioration. The suggested techniques include examination using X-ray radiography, CT scanning and the analysis of samples using scanning electron microscopy (SEM). The photographic documentation showed the head has recently started to deteriorate. The examination formed the basis for conservation, preservation and the ongoing study of the head.
\end{abstract}

Keywords: Museum of Criminology, Fotios Giagoulas, mummification process, conservation, X-ray, CT scan, SEM

\section{INTRODUCTION}

Since 1992, the mummified head of a Greek bandit, Fotios Giagoulas, has been on display at the Museum of Criminology, which is affiliated to the Department of Forensic Medicine and Toxicology, School of Medicine, University of 
Athens. The Museum of Criminology was founded in 1932 by the Professor of Forensic Medicine and Toxicology, Ioannis Georgiadis, who collected $19^{\text {th }}$ and $20^{\text {th }}$ century criminological evidence from Greece (17).

This investigation aims to present the examination plan for the mummified head in order to preserve and conserve it using analytical techniques, which will provide important information about the mummification process, level of preservation, conservation requirements, and the recognition of biological deterioration.

\section{The life of Fotios Giagoulas}

Fotios Giagoulas, known as Fotos, Fotis and the "King of Mountains", was a legendary bandit during the $1920 \mathrm{~s}$. He was born on $12^{\text {th }}$ October 1900 in the village of Metaxa, near Servia, Kozani. He started his criminal career with an "honour killing"; a lieutenant of the gendarmerie in Athens, who had raped his cousin. Thereafter, he became notorious and lived as an outlaw from 1920 until his death in 1925 (18).

He was mainly active in the area around Mount Olympus (Fig. 1-2) with murders, robberies and kidnappings in his criminal record. He caused fear in Greek high society, but many argue that he helped many poor families, leading him to be likened to a Greek "Robin Hood". He died whilst fighting with his gang on $21^{\text {st }}$ of September 1925 during a brawl with gendarmes in Kleftovrysi, Olympus. His death signified the end of the bandits' era in Greece. Many books, articles and songs were written about his beauty, intelligence and action, making him a legendary personality of recent Greek history. His infamous reputation continued posthumously (18).
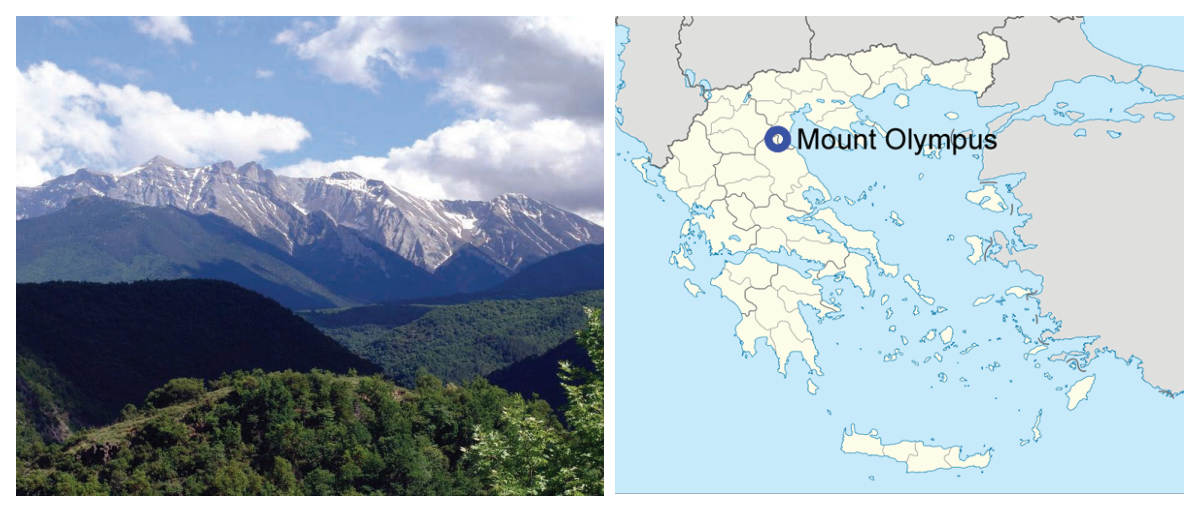

Figure 1-2. The "kingdom" of Giagoulas, Mount Olympus. 


\section{MATERIALS AND METHODS}

\section{The head of Fotios Giagoulas}

During the life of Giagoulas, the typical punishment for criminals in Greece was decapitation and public castigation (Fig. 3). In September 1925, the decapitated head of Giagoulas' and his accomplices were placed on a wooden bench in front of Katerini train station before being impaled on the iron railings. Later on, the Gendarmerie ordered that the bandits' heads be placed in tins with rock salt and sent to the Department of Forensic Medicine and Toxicology, Athens for identification and forensic examination (18).

The forensic pathologists studied the heads in order to interpret evidence in line with the theory of the Italian criminologist Cesare Lombroso. He claimed that criminality was inherited, and that someone who is a "natural-born criminal" could be identified by physical defects (2). Giagoulas' head was examined macroscopically for the determination of such physical features. The skin was removed exposing the calvarium, which was then opened by a sawing method, to enable the brain to be studied. The Professor and Director of the Forensic Laboratory, Ioannis Georgiadis, noted in his Clinical Forensic Toxicology (1925, Athens), that such an undertaking required the placement of a receptacle at the bottom of the split head for collecting fluids, which were then stored in a special container for toxicological analysis (18).

Since 1925, no further research has been conducted on the decapitated heads. Museum records show that the heads were moved on several occasions between 1925 and 1992. During this time, they were stored in cardboard boxes, prior to their display in the museum as permanent exhibits.

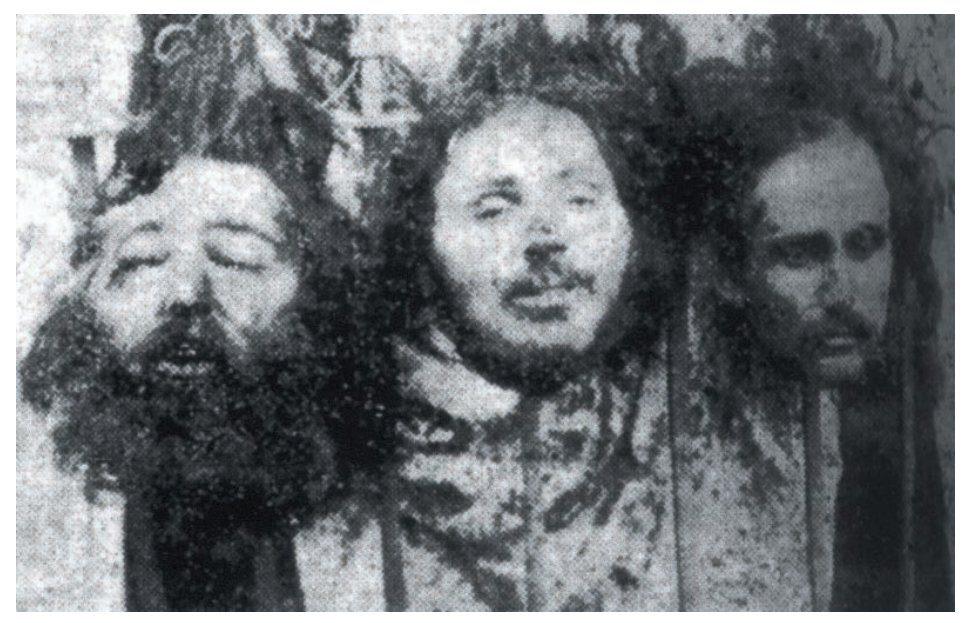

Figure 3. The decapitated heads of the Giagoulas' gang with the head of Fotios Giagoulas in the centre. 
A 'best practice' methodology for the study and conservation of the mummified head

The conservation of mummies is a politically and ethically sensitive issue (6). The preservation of a mummy following scientific investigation involves:

(1) Identification of the type of mummification process used and the level of preservation;

(2) Selection of an appropriate method of study;

(3) Individualisation of restoration;

(4) Recommendation of storage conditions, including environmental and pest protection.

Finally, storage conditions respect the laws and beliefs of the nation (14) to which the human remains belong.

\section{The current display of the mummified head}

The Museum of Criminology is in an enclosed room, which exhibits various materials including metal, fossils, human remains, paper and textiles (Fig. 4a). The museum opens to the general public sporadically. In 1999, the Department of Conservation of Antiquities and Works of Art at the Technical and Educational Institute of Athens (TEIA) established a programme, in collaboration with the Department of Forensic Medicine and Toxicology of Athens, in order to improve, develop and upgrade the Museum of Criminology, to preserve its collections and to enhance the display of objects (17). From 2007 to 2008, the listing and digitization of exhibits was completed. The heads of Giagoulas and his gang are currently displayed in a wooden case with poor quality glass panels (Fig. 4b) alongside other mummified and skeletal remains. Whilst the museum does not possess climate control equipment, two temperature and humidity monitors were installed in the vicinity of the display case in 2007. According to Conservator-Museologist Zoe Sakki seasonal fluctuations of temperature and humidity are apparent (16). In 2013, a screening of microbial contamination began.

\section{Study method}

The following steps were followed prior to the examination of the head:

(1) Study of the macro- and micro-climate of the museum, and the display case. It was important to not expose the head to radical changes of humidity and temperature during its examination. 
(2) The construction of an appropriate protective case for storage and transportation. Several protective materials were used for the safety of mummy's transportation, in order to absorb shock and vibration including polyethylene foam products and radiation bags.

(3) Photography allowed the observation of vulnerable areas, the measurement of facial features and the estimation of preservation status without having therefore intervention on the exhibit itself. This was performed in order to assess the recent degradation changes to the head using a SONY, SLT-A58 digital camera with DT 3.5-5.6/18-55 lens. During the photography, gloves and a mask were worn.

(4) Macroscopic observation and recording of the preservation status. It was necessary to record the products of decay e.g. the extent, shape, colour etc.

(5) Collection of samples from skin, hair or bone, if possible.

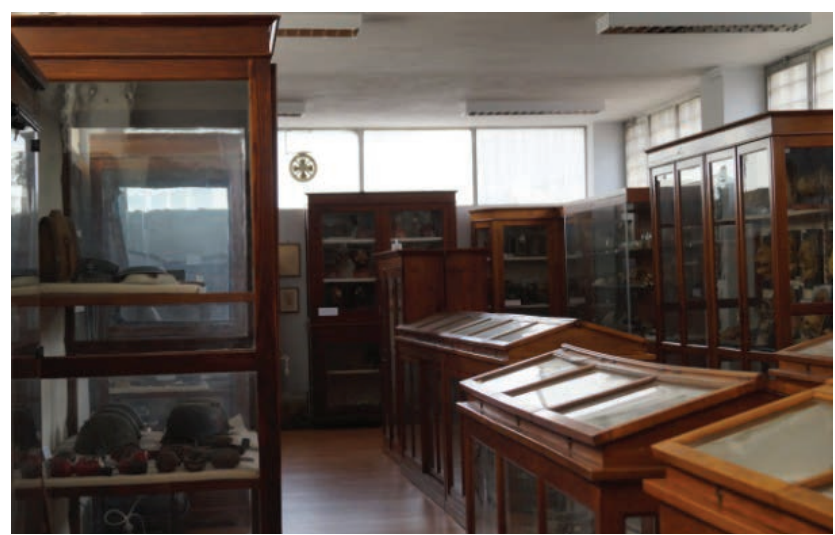

Figure 4a. The inside Museum of Criminology.

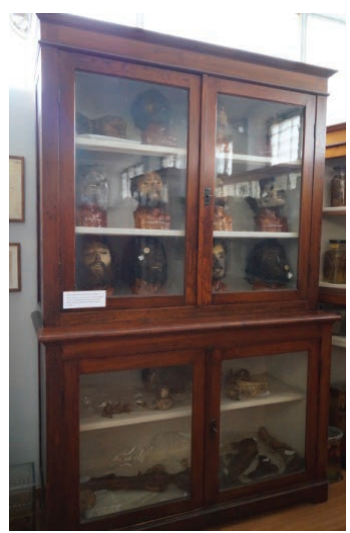

Figure $\mathbf{4 b}$. The display case with the mummified heads.

\section{RESULTS}

Giagoulas' head is placed on an exhibition base of unknown material, probably gypsum, which imitates a human neck and part of his thorax. The hair, beard, moustache and eyelashes are also preserved. Until 2011, the skin belonging to the head was stable. Minor dark areas on the cheeks and dark spots on the nose were observed without signs of expansion (Fig. 5). By 2013, changes were recorded in the condition of the head. During a recent visit in 2014, it was obvious that most of the surface of Giagoulas' head had begun to deteriorate. Despite this, the mummified head is well-preserved. 


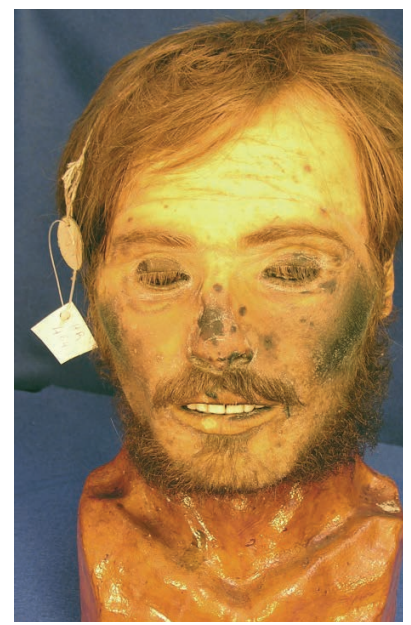

Figure 5. The Giagoulas' head in 2007.

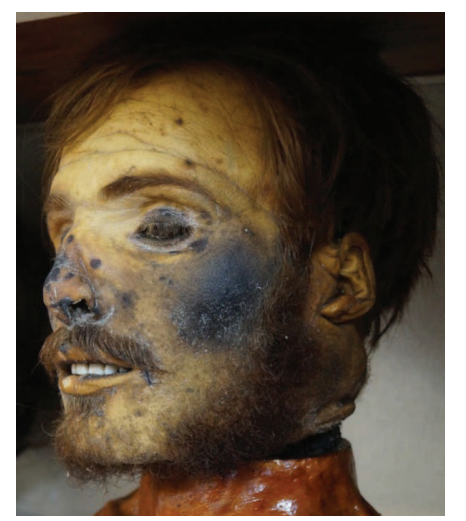

Figure 7. The left side of Giagoulas' head.

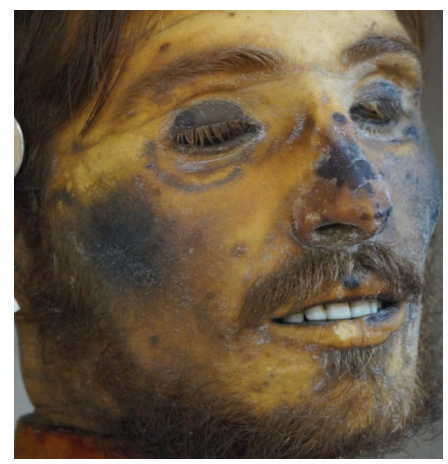

Figure 9. Details of Giagoulas' head.

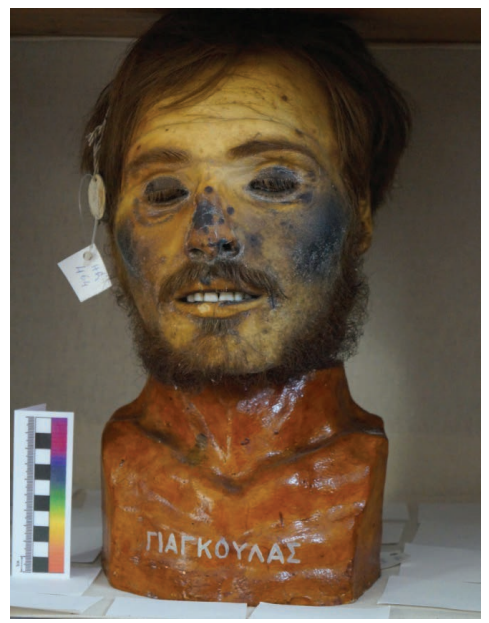

Figure 6. The Giagoulas' head in 2014.

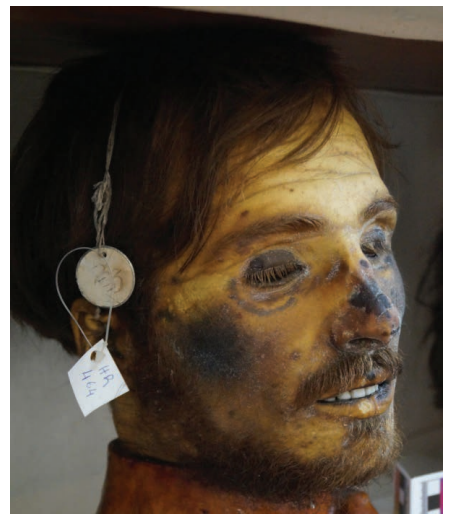

Figure 8. The right side of Giagoulas' head.

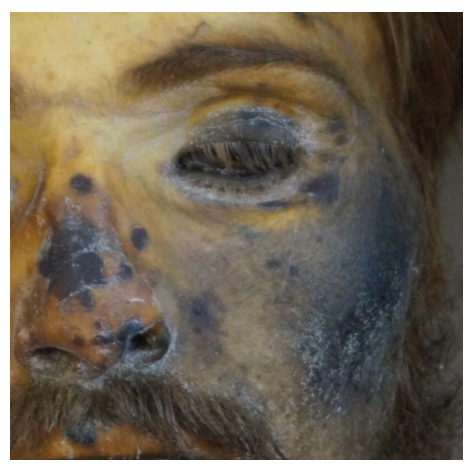

Figure 10. The eyes of Giagoulas were preserved. 


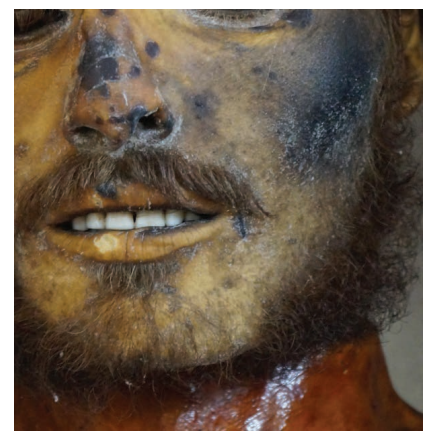

Figure 11. The vulnerable skin areas on the cheeks and on the nose.

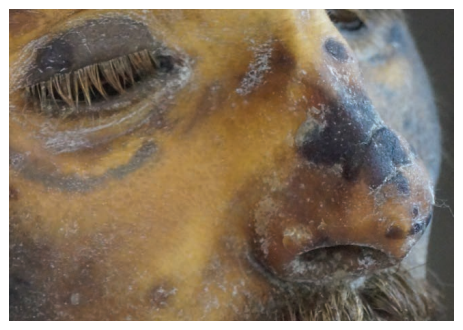

Figure 12. Signs of decay among the facial wrinkles.

The assessment of the current conservation status was based on macroscopic observation and comparison between the recent and the older photographs of Giagoulas' head. The intense smell of decay, the absence of a very recent microbial study in the museum and also poor lighting of the museum did not allow an overall photographic documentation or recording. Moreover, moving the head or exposing it to the museum's atmosphere would be too risky because of the poor conservation state.

According to the recent photographs of Giagoulas' head it is obvious that head has started to deteriorate. The head skin is discoloured in various ways. The vulnerable dark areas have expanded on the cheeks and on the eyelids (Fig. 5-6). Many dark spots, especially on the nose, have been noticed (Fig. 7-12). White signs of decay (probably fungi) have also appeared in several areas of the head, mainly between the facial wrinkles of the eyes and of the nose (Fig. 11, 12). Generally, the head is preserved more deformed at the left side of the face than the right side. It is worth pointing out that during the photography it was noticed that the eyes are still preserved (Fig. 9, 10). There were no noticeable signs on the skull which would confirm the exportation and the examination of the brain in 1925 .

\section{DISCUSSION AND FUTURE WORK}

The primary factors that contribute to the continuous degradation of the head are exhibition in an improper display case alongside other poorly conserved heads; the improper mount in use; and the radical fluctuation of temperature and humidity inside the museum. The absence of dedicated conservation staff and lack of financial support contribute to these issues. 
Future examination of all the mummified heads in the display case is planned. The investigation of the corrosion and its by-products will enable an appropriate conservation method to be applied. The use of radiography and CT scanning have proven useful in other mummy studies as non-destructive ways of detecting ancient diseases and embalming methods, alongside visualising the internal structure of such artefacts $(3,4,8,9,10)$. In the case of Giagoulas' mummified head, we expect to gain information about the position of the head on the exhibition base, the internal filling materials, the possible injuries from the head nailing and the incision of the skull after the removal of the brain for forensic examination in 1925.

In addition, the heads would provide information regarding the lives of these individuals through examination of skin, hair and teeth samples using the following techniques:

- Scanning electron microscopy (SEM) or/and energy dispersive X-ray (EDX) analysis could provide information about the morphology and microstructure of samples, the conservation status, the microbial deterioration, the probable mechanisms of mummification $(5,7,11-13,15)$.

- DNA analysis may reveal evidence regarding their origin, health and possible familial links (1).

- Forensic study of Giagoulas' injuries caused by the knife with which he was beheaded would present interesting lines of enquiry as some reports state he was beheaded using his own knife, which is also exhibited in the museum (Fig. 13).

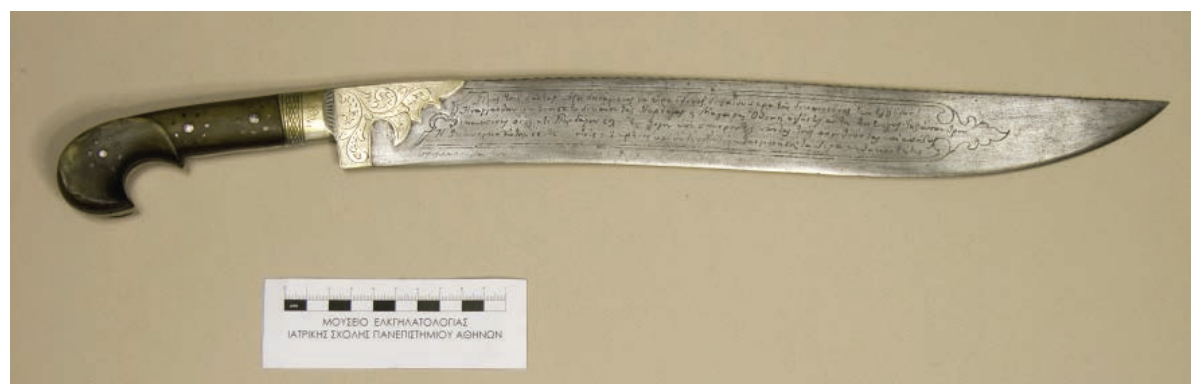

Figure 13. The knife of Fotios Giagoulas, named Pardala.

\section{CONCLUSION}

The poor conservation status of Giagoulas' head and its continuous deterioration demand immediate study and conservation. The preservation of the remains of this controversial and famous Greek bandit is a source of historical 
data for early $20^{\text {th }}$ century Greece. By leaving it to its fate we would irrevocably lose a very significant part of our recent Greek history and tradition.

\section{ACKNOWLEDGEMENTS}

The authors would like to thank Sotirios Athanaselis, Associate Professor of Toxicology, Department of Forensic Medicine and Toxicology, for historical information. Giwrgos Fakorelis, Assistant Professor of Chemistry of the Department of Conservation of Antiquities and Works of Art, at TEI of Athens, for providing useful articles about microbial contamination and deterioration. Dr Maria Pretzler, Senior Lecturer in Ancient History at Swansea University, Wales, for correcting this paper and the Conservator and Museologist, Zoe Sakki, for information and bibliography on the Museum of Criminology. Finally we would like to thank the Archaeologist and Museologist Iwanna Dalamitra, as well as the Conservators of Archaeological Antiquities and Works of Art Jean Loizou, Giwta Karapanou, Marina Leveidiotou and Popi Bardava for their valuable help and support in the preparation of this paper.

\section{REFERENCES}

1. Aufderheide A.C. (2003). The Scientific Study of Mummies. Cambridge University Press. Cambridge.

2. Albrecht A. (1910). Cesare Lombroso. J Crim L \& Criminology, 1 (2), 74-83.

3. Beckmann E.C. (2006). CT scanning the early days. Brit J Radiol, 79 (937), 5-8.

4. Böni T., Rühli F.J., Chhem R.K. (2004). History of paleoradiology: early published literature, 1896-1921.Can Assoc Radiol J, 55, 203-210.

5. Bozzola J.J., Russell L.D. (1992). Electron Microscopy: Principles and Techniques for Biologists. Jones and Bartlett Publishers. Massachusetts.

6. Cassman V., Odegaard N. (2004). Human Remains and the Conservator's Role. Stud Conserv, 49 (4), 271-282.

7. Chang B.S., Uhm C.S., Park C.H., Kim H.K, Lee G.Y., Cho H.H., Kim M.J., Chung Y.H., Song K.W., Lim do S., Shin D.H. (2006). Preserved skin structure of a recently found fifteenth century mummy in Daejeon, Korea. J Anat, 209 (5), 671-680.

8. Chhem R.K. (2006). Paleoradiology: imaging disease in mummies and ancient skeletons. Skeletal Radiol, 35 (11), 803-804.

9. Chhem R.K., Brothwell D.R. (2007). Paleoradiology: imaging mummies and fossils. Springer-Verlag. Heidelberg.

10. Cosmacini P., Piacentini P. (2008). Notes on the history of the radiological study of Egyptian mummies: from X-rays to new imaging techniques. Radiol Med, $113(5), 615-626$. 
11. David A.R. (1979). Manchester Museum Mummy Project: Multidisciplinary Research on Ancient Egyptian Mummified Remains. Manchester University Press. Manchester.

12. Hayat M.A. (1970). Principles and Techniques of Electron Microscopy, Biological Applications. van Nostrand Reinhold. New York.

13. Hino H., Ammitzbøll T., Møller R., Asboe-Hansen G. (1982). The ultrastructure of bacterial spores in skin of an Egyptian mummy. Acta Pathol Microbiol Immunol Scand, 90 (1), 21-24.

14. Lombardi G.P. (2001). Mummy Conservation and Paleopathology. Chungarà, $33(1), 87-89$.

15. Papageorgopoulou C., Xirotiris N.I., Iten P.X., Baumgartner M.R., Schmid M., Rühli F. (2009). Indications of embalming in Roman Greece by physical, chemical and histological analysis. J Archaeol Sci, 36 (1), 35-42.

16. Sakki Z., Karydis C., Spiliopoulou C., Maravelias C. (2007). Knives Cost Lives: Ethical Issues Relating to the Conservation of Group of Weapons at the Museum of Criminology of the Medical School-University of Athens. In: CSSIM Strategies for Saving Our Cultural Heritage, International Conference on Strategies for Saving Indoor Metallic Collections with a Satellite Meeting on Legal Issues in the Conservation Of Cultural Heritage, 25 February-1 March 2007, Cairo, Egypt, 1-7.

17. Stamatopoulou E., Argyropoulos V., Panagiaris G., Papadakos N., Christodoulou P., Koutselinis A. (2003). Low-budjet collection management at the Museum of Criminology, School of Forensic Medicine, University of Athens. Museologia, 3, 95-100.

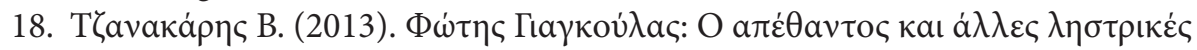

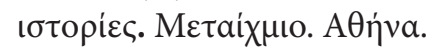

\section{Address for Correspondence:}

Prof. Maria Stefanidou

Museum of Criminology

Department of Forensic Medicine and Toxicology

School of Medicine

University of Athens

75 Mikras Asias street, 11527 Goudi, Athens, Greece

E-mail:mstefan@med.uoa.gr 